\title{
Application of thermal microcautery in migraine
}

management

Aplicação da microcauterização térmica no manejo da

\section{migrânea}

Eleni Papageorgiou'

Konstantine Kovas ${ }^{1}$

Camillus Power ${ }^{2}$

Nikolaos Kostopoulos ${ }^{3}$

'Dept. of Neurology, General Hospital of Athens, G. Gennimatas, Greece.

${ }^{2}$ Dept. of Pain Medicine, Tallaght University

Hospital, Dublin, Ireland.

${ }^{3}$ Holistic Health Centre, Athens, Greece

\section{*Correspondence}

Eleni Papageorgiou

E-mail: helenmorou@yahoo.gr

Received: December 5, 2019.

Accepted: December 26, 2019.

DOI: $10.5935 / 2178-7468.20190026$

\section{ABSTRACT}

Thermal microcautery is a novel minimally invasive intervention for migraine. We present a case series of twenty-one patients who underwent this technique. Nineteen patients reported improvement in migraine management. Of these four patients went on to complete remission and a further eleven patients reported over 50\% improvement. In addition, the majority of patients noted reductions in intensity and duration of headache with a better response to medication. The efficacy of thermal microcautery generates a new hypothesis that attempts to explain how a neuromodulation technique may be helpful in the management of migraine.

Keywords: Thermal microcautery; Migraine; Neuromodulation.

\section{RESUMO}

A microcauterização térmica é uma nova intervenção minimamente invasiva para enxaqueca. Apresentamos uma série de casos de vinte e um pacientes submetidos a essa técnica. Dezenove pacientes relataram melhora no tratamento da enxaqueca. Desses quatro pacientes, a remissão foi concluída e outros onze relataram mais de $50 \%$ de melhora. Além disso, a maioria dos pacientes observou reduções na intensidade e duração da dor de cabeça com uma melhor resposta à medicação aguda. A eficácia da microcauterização térmica gera uma nova hipótese que tenta explicar como uma técnica de neuromodulação pode ser útil no tratamento da enxaqueca.

Descritores: Microcauterização térmica, enxaqueca, neuromodulação. 


\section{INTRODUCTION}

Migraine is a highly disabling disease, with high financial and social impact (1). Migraine treatment can be both acute and preventive, several pharmacological classes can be effective, as also may non-pharmacological therapies $(2,3)$. Nerve blocks, botulinum toxin type A, and neuromodulation may play an important role in the management of migraine (4).

A number of studies have come to light, showing that external stimulation of certain parts of the head, may contribute to the management of pain $(5,6,7,8)$ Thermal microcautery have been used for the treatment of pain disorders, but limited information is available about its role in migraine treatment (9). We aimed in this study to present our experience in a case series of patients treated with thermal microcautery.

\section{METHODS}

\section{Sample}

Patients were selected from the Neurological Headache outpatient clinic of G.N.A. "G. Gennimatas", from November 2017 up to March 2019.

\section{Inclusion / exclusion criteria}

The inclusion criteria were as follows -

1. Diagnosis of chronic migraine with or without aura and/or Medication Overuse Headache $(\mathrm{MOH})$.

2. The failure of at least one preventive treatment.

3. Patients were not allowed to undergo Botox injections $(10,11)$ Acupuncture and Transcutaneous Electrical Nerve Stimulation for at least 3 months.

\section{Technique description}

In this technique we applied instantly intense heat $\left(600^{\circ} \mathrm{C}\right.$ ) to an area of localized pain (2) identified by clinical examination before the procedure. The heat was applied by a low temperature cautery disposable fine tip pen, Fiab Disposable electrocautery pensF7255 (28 $\mathrm{mm}$ ) which is routinely used in dermatology for microsurgery.

Thermal microcautery was performed on bilateral cervical, occipital, supraorbital and temporal areas, (12) depending on what patients referred to as the most painful points during the attack of migraine and also between acute attacks.

Post procedure a cooling cream was applied (1gr., Pistacia Lentiscus, Shorea robusta)

It was planned that each patient would undergo 4 sessions, every 7-10 days. Each patient had a recording of the frequency, duration, intensity of episodes of headache, medication use and response. We recorded the VAS pain score in each session.
The protocol of the study had been submitted to the Hospital's Ethical Committee and had been approved. All patients were fully informed about the aim of the study, the procedure and the complications and had filled out a consent form.

\section{RESULTS}

Twenty-one patients have completed the study over a two-month period with follow-up on all patients for six months (twenty female patients - one male). The age ranged from 37 to 68 years old (average 51.1 years old). All of them had received at least one preventive therapy: six patients used propranolol, twelve topiramate, three valproic acid, five flunarizine, four amitriptyline, thirteen SSRIs-SNRIs, five botulinum-A. Additional, five patients had undergone Acupuncture and two used cannabis oil on a daily basis. None of them had undergone any invasive therapy or used anti-CGRP antibodies.

Fourteen patients used triptans at the acute phase of the episode, all of them paracetamol and/or NSAIDs and two Cephaly.

Fifteen of twenty-one patients had a combined diagnosis of migraine and $\mathrm{MOH}$.

Nineteen of twenty-one patients reported overall improvement of their symptoms.

Four patients reported complete remission of their migraine which has persisted for six months.

Eleven patients reported over 50\% improvement (reduction in the frequency, intensity and/or duration of headaches) and four patients reported a $30 \%$ improvement.

Evaluation of Migraine symptoms at the end of the study (21 patiens)

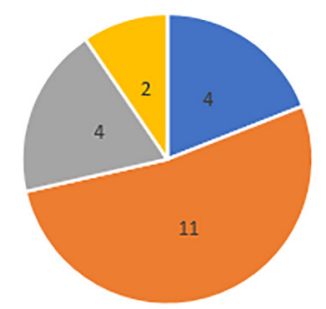

a complete remission $\|>50 \%$ improvement $\|>30 \%$ improvement $\|$ no improvement

Figure 1. Pie graph of evaluation of Migraine symptoms at the end of the study (21 patients)

15 patients out 19 who reported improvement, recorded a reduction in the frequency of episodes, 16 a reduction in the intensity of the pain, 9 a reduction in the duration of each episode.

15 patients noted a better response to the drugs administered at the acute phase of pain,

Five patients were able to stop their preventive treatment in six months.

Patients tolerated the procedure well including application of the cooling cream. Five patients 


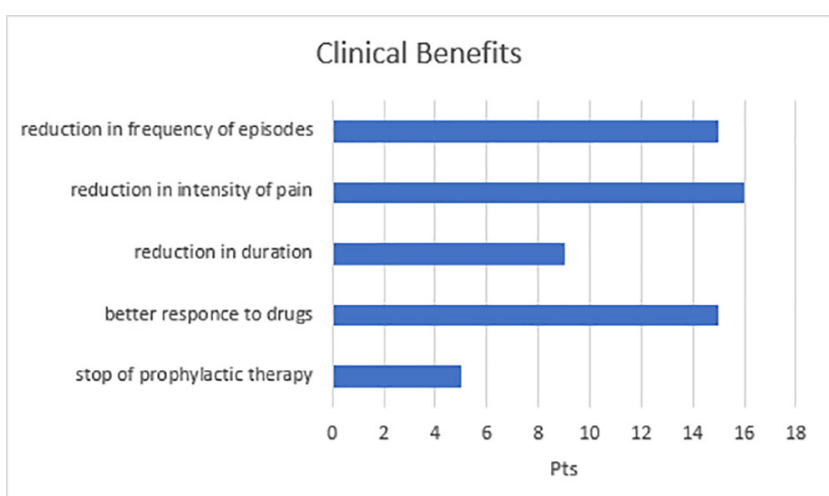

Figure 2. Bar graph of the clinical benefits of treatment.

experienced relief of migraine immediately following the procedure.

The mild burn after the application of cauterization was healed in 2-3 days, leaving no aesthetic marks. No skin reactions appeared.

\section{DISCUSSION}

The present study shows promising results with thermal microcautery in migraine preventive treatment, due to its efficacy and tolerability (13).

Explanations for our findings may include the theory of the distorted communication within the trigeminocervical complex. A possible pathophysiological mechanism of action is the modification of the perception of pain through peripheral stimulation $(1,14)$ in the regions of distribution of trigeminal and occipital nerves $(12,15)$. Through the anatomical and functional convergence of these nerve endings, a wider distribution of the stimulus is supposed to trigger centrifugal pathways that regulate pain (16). It is known that stimulation of the occipital nerves regulates the activity of sensory neurons in the trigeminocervical complex; so, stimulation of the trigeminal nerve as well, is supposed to have the same effect. Its branches in the trigeminal divisions and $\mathrm{C} 1$ and C2 dermatomes (9) converge with sensory fibers of the dura mater and share the same receptive field. Thus, it is possible that an extracranial stimulation such as thermal microcautery can also modify the activity of the sensory fibers of the dura.

Migraine originates in a distorted communication within a complex neural network which leads to the well described neuro-vascular cascade of events (17). We hypothesize that a thermal microcautery stimulus resets this network restoring its natural homeostasis.

The study has several limitations, first it is not controlled by a sham procedure or other treatment as a comparator. A baseline phase before the treatment performed has not been performed, so a possible recall bias may affect our results.

Conclusion

Thermal microcautery is a promising therapy for migraine, further randomized clinical studies are necessary to confirm its efficacy

\section{REFERENCES}

1. 1. Ellens, D. J., \& Levy, R. M. (2011). Peripheral neuromodulation for migraine headache. In Peripheral Nerve Stimulation (Vol. 24, pp. 109-117). Karger Publishers. DOI: 10.1159/isbn.978-38055-9489-9

2. Melzack, R., \& Wall, P. D. (1965). Pain mechanisms: a new theory. Science, 150(3699), 971-979. DOI: 10.1126/ science.150.3699.971

3. Lovati, C., D’Amico, D., \& Bertora, P. (2009). Allodynia in migraine: frequent random association or unavoidable consequence?. Expert review of neurotherapeutics, 9(3), 395-408. https://doi.org/10.1586/14737175.9.3.395

4. Goadsby, P. J., Holland, P. R., Martins-Oliveira, M., Hoffmann, J., Schankin, C., \& Akerman, S. (2017). Pathophysiology of migraine: a disorder of sensory processing. Physiological reviews, 97(2), 553-622. DOI: 10.1152/physrev.00034.2015

5. Lipton R, Goadsby PJ, Cady R, Aurora SK, Grosberg BM, F., \& F G, et al. (2009). PO47 PRISM study: occipital nerve stimulation for treatment-refractory migraine. Cephalalgia, 29(Suppl 1), 30. Retrieved from http://journals.sagepub. com/doi/pdf/10.1111/J.1468-2982.2009.01960.X

6. Nayak, R., \& Banik, R. K. (2018). Current Innovations in Peripheral Nerve Stimulation. Pain Research and Treatment. Hindawi Limited. https://doi.org/10.1155/2018/9091216

7. Lauritsen, C. G., \& Silberstein, S. D. (2019, May 1). Rationale for electrical parameter determination in external trigeminal nerve stimulation (eTNS) for migraine: A narrative review. Cephalalgia. SAGE Publications Ltd. https://doi. org/10.1177/0333102418796781

8. Rapoport, A. M., Lin, T., \& Tepper, S. J. (2020). Remote Electrical Neuromodulation (REN) for the Acute Treatment of Migraine. Headache: The Journal of Head and Face Pain.

9. Ishiyama, S., Shibata, Y., Ayuzawa, S., Matsushita, A., \& Matsumura, A. (2018). Clinical Effect of C2 Peripheral Nerve Field Stimulation Using Electroacupuncture for Primary Headache. Neuromodulation, 21(8), 793-796. https://doi. org/10.1111/ner.12772

10. Loeb, L. M., Amorim, R. P., Mazzacoratti, M. da G. N., Scorza, F. A., \& Peres, M. F. P. (2018). Botulinum toxin a (BT-A) versus low-level laser therapy (LLLT) in chronic migraine treatment: A comparison. Arquivos de NeuroPsiquiatria, 76(10), 663-667. https://doi.org/10.1590/0004282×20180109

11. Zidan, A., Roe, C., Burke, D., \& Mejico, L. (2019). OnabotulinumtoxinA wear-off in chronic migraine, observational cohort study. Journal of Clinical Neuroscience, 69, 237-240. DOI: 10.1016/j.jocn.2019.07.043

12. Popeney, C. A., \& Aló, K. M. (2003). Peripheral neurostimulation for the treatment of chronic, disabling transformed migraine. Headache, 43(4), 369-375. https:// doi.org/10.1046/j.1526-4610.2003.03072.x

13. Fishman, M. A., Antony, A., Esposito, M., Deer, T., \& Levy, R. (2019). The Evolution of Neuromodulation in the Treatment of Chronic Pain: Forward-Looking Perspectives. Pain Medicine (Malden, Mass.), 20(1), S58-S68. https://doi. org/10.1093/pm/pnzO74

14. Popeney, C. A., \& Aló, K. M. (2003). Peripheral neurostimulation for the treatment of chronic, disabling transformed migraine. Headache: The Journal of Head and Face Pain, 43(4), 369-375. https://doi.org/10.1046/j.15264610.2003.03072.x

15. Slavin, K. V., Nersesyan, H., \& Wess, C. (2006). Peripheral neurostimulation for treatment of intractable occipital neuralgia. Neurosurgery, 58(1), 112-118. https://doi. org/10.1227/01.NEU.0000192163.55428.62 
16. Landy, S., Rice, K., \& Lobo, B. (2004). Central sensitisation and cutaneous allodynia in migraine. CNS drugs, 18(6), 337-342. https://doi.org/10.2165/00023210-20041806000001
17. D'Andrea, G., D'Arrigo, A., Dalle Carbonare, M., \& Leon, A. (2012). Pathogenesis of migraine: role of neuromodulators. Headache: The Journal of Head and Face Pain, 52(7), 11551163. https://doi.org/10.1111/j.1526-4610.2012.02168.x 